\title{
Sistema Único de Saúde: espaços decisórios e a arena política de saúde
}

\author{
The Unified National Health System: \\ decision-making forums and the \\ political arena in health
}

\footnotetext{
1 Programa de Pós-graduação em Sociologia, Universidade Federal do Rio Grande do Sul, Porto Alegre, Brasil.

Correspondência S. V. Côrtes

Programa de Pós-graduação em Sociologia, Universidade Federal do Rio Grande do Sul. Av. Bento Gonçalves 9500

Porto Alegre, RS

91509-900, Brasil.

scortes@via-rs.net
}

\section{Abstract}

This article analyzes the creation of new political arenas in the Brazilian health sector as well as shifts in power relations among state and social political actors in the context of public health system reform, focusing on the last two decades. The three main conclusions are the following: The creation of forums in which government actors can establish agreements that allow the shared national, State, and municipal coordination of management measures have strengthened the positions of these actors in the health political arena. Social actors, led by representatives of professional health societies, were both urged (and also took the initiative) to submit their demands and proposals through participatory forums that dealt mainly with secondary political issues, thus steadily losing the capacity to influence the real decision-making process in the sector. Market stakeholders took little part in the participatory forums, rather preferring to exert their influence directly on public decision-makers and to implement adaptive strategies to increase their profits.

Single Health System; Health Policy; Health Councils; Health Personnel

\section{Introdução}

O presente artigo procura colaborar no esforço de compreensão sobre os processos sociais e políticos que se desenrolaram ao longo das duas décadas de existência do Sistema Único de Saúde (SUS). Para isso, focaliza as trajetórias de duas instâncias colegiadas de nível federal: o novo Conselho Nacional de Saúde (CNS), criado em 1990, e a Comissão Intergestores Tripartite (CIT), constituída em 1993. Sua criação está relacionada a características fundamentais do desenho institucional do sistema, quais sejam, a institucionalização de mecanismos participativos e a gestão descentralizada. $\mathrm{O}$ artigo analisa o impacto do processo de consolidação do papel institucional desses fóruns sobre a arena política da área e sobre a configuração das relações entre atores estatais e societais no âmbito do SUS. Examina ainda a ação desses atores e de comunidades de política no âmbito desses fóruns e fora deles, visando a aumentar seu poder de influência sobre o processo decisório setorial.

Mecanismos de participação e de gestão descentralizada não são peculiaridades da área de saúde. Entretanto, o pioneirismo na sua construção e implementação tornou a área uma espécie de modelo inspirador de outros setores de política pública para a construção de mecanismos similares. A institucionalização dos dois fóruns aqui focalizados impactou sobre o modo como foi se configurando a arena política de saúde, 
enquanto eles mesmos se constituíram como subarenas de mediação e de decisão política e foram assumindo diferentes papéis nessa arena ao longo do período.

$\mathrm{O}$ artigo está dividido em quatro seções. Após esta Introdução é apresentada a perspectiva teórico-conceitual utilizada na análise. A seguir são examinados os processos de constituição do CNS e da CIT e as transformações sofridas pela arena política setorial. Ao final são apresentadas as considerações finais.

\section{Atores e configurações sociais em contextos institucionais}

O conceito de arenas políticas é normalmente empregado sem qualquer preocupação em defini-lo ou situá-lo no contexto de algum referencial teórico (em uma pesquisa em periódicos filiados ao indexador SocINDEX a noção "policy arena" foi utilizada deste modo por 180 dos 183 artigos que incluíam o conceito em seus resumos). $\mathrm{O}$ uso em geral é metafórico, no sentido de ressaltar a existência de espaços conflitivos estatais, societais ou, mais freqüentemente, espaços de interconexão entre as duas esferas, nos quais proposições, atores e grupos de interesse disputam a primazia de suas posições. Neste trabalho, o conceito de arena política também se refere à noção de espaço político conflituoso ${ }^{1}$, mas a ênfase recai sobre o papel dos atores e dos espaços decisórios em processos que levam à definição e redefinição de estruturas setoriais de relações entre tais atores e espaços políticos 2 , no caso na área de saúde. Essas arenas setoriais têm os governos e particularmente o Governo Federal como decisor fundamental em torno dos quais se organizam as disputas. O conceito remete às noções de processo, de transformação constante e de demarcação difusa de participantes e de fronteiras entre Estado e sociedade e entre setores de política pública.

Tais participantes são aqui tratados como atores estatais e societais ou como atores em rede. O conceito de atores estatais pode ser atribuído tanto àqueles que ocupam cargos de direção em órgãos dos três Poderes republicanos quanto aos que, dependendo do conceito de Estado adotado, participam na construção de consensos que mantêm a hegemonia da classe dominante 3 ou da ação formadora de disposições sociais duráveis, que impõem e inculcam os princípios de hierarquização social 4 . No entanto, considerando a natureza dos fóruns aqui examinados, os atores estatais que neles participam são predominantemente governamentais, atuando como gestores de saúde de nível federal, estadual ou municipal, ou como gestores públicos que não atuam diretamente na área.

O conceito de atores societais não expressa diferenças essenciais entre dois tipos de atores: os sociais e os de mercado. Enquanto os primeiros estão associados ao conceito de "sociedade civil", os segundos estão relacionados com a noção de economia de mercado. Sem assumir a carga normativa por vezes aferida ao conceito de sociedade civil - criticada por atribuir positividade ao conceito em contraposição à negatividade conferida às instituições políticas 5,6,7,8,9 - este trabalho considera que a sociedade civil e seus atores seriam diferentes do Estado e do mercado, e de seus atores. Os atores estatais e de mercado seriam compelidos a agir em ambientes regidos pelo poder e pelo dinheiro, enquanto o mesmo não aconteceria com os atores sociais. Atores sociais não visam a tomar o poder do Estado ou organizar a produção, mas, sim, “...exercer influência por meio da participação em associações e movimentos democráticos" 10 (p. 427).

A literatura aponta como os atores sociais mais influentes nas arenas políticas da área de saúde 11,12 organizações de profissionais e trabalhadores de saúde; entidades de trabalhadores, não especificamente da área da saúde; associações comunitárias; movimentos sociais; entidades de portadores de patologias, deficiências, étnicas e de gênero. Os atores de mercado mais influentes seriam os prestadores de serviços, seguradoras de saúde e também organizações de empresários, com interesses não diretamente vinculados à área de saúde.

No entanto, existem atores cuja posição no contexto da política não pode ser determinada em relação ao Estado, ao mercado ou à sociedade civil. Segundo Heclo 13, seriam comunidades de políticas que agem em contextos de redes de políticas. O conceito de comunidade de política refere-se a um número limitado e relativamente estável de membros que compartilham os mesmos valores e visão sobre quais deveriam ser os resultados da política setorial 14 . Comunidades de políticas participam das redes de políticas, tentando afetar processos decisórios que se tornaram muito segmentados, na medida em que as políticas são elaboradas “...por uma miríade deorganizações interconectadas e interpenetradas” 15 (p. 53). Podem existir diferenças dentro da comunidade, especialmente relacionadas a "questões administrativas" 16 (p. 9), as quais tendem a se transformar em clivagens partidárias, ou entre facções de partidos. No entanto, a unidade mantém-se enquanto houver consenso político e ideológico em torno de uma determinada visão sobre a explicação para os principais problemas 
da área em que atua e, principalmente, sobre um conjunto básico e essencial de propostas.

As noções de comunidade e rede de política, tendo em vista o modo como foram originalmente desenvolvidas por Heclo 13 , Jordan \& Richardson 15 e Rodes 14 , foram redefinidas ou atualizadas por diversos autores que procuravam entender como se processam as decisões nas diversas áreas de políticas públicas e nos centros decisórios gerais dos Governos. Como afirmam True et al. 17 (p. 158), elas podem ser denominadas "como triângulos de ferro, nichos temáticos, subsistemas políticos, redes temáticas”, mas “... qualquer que seja a denominação adotada, ela se refere a uma comunidade de especialistas operando fora do processo político visível, em contextos nos quais a maior parte das questões de cada política setorial específica é tratada no interior de uma comunidade de experts".

$\mathrm{Na}$ área da saúde, comunidades e redes de políticas incluem indivíduos de várias instituições, áreas de conhecimento ou profissões. Eles podem trabalhar na prestação de serviços, liderar organizações da sociedade civil, atuar como pesquisadores e acadêmicos ou como gestores. As redes de política são formadas pelas relações complexas que se estabelecem entre companhias farmacêuticas, profissionais, prestadores privados de serviços hospitalares, associações de portadores de patologias, dentre outros grupos de interesse, e comunidades de políticas, que têm membros dentro e fora do Governo 12 .

No Brasil, durante as três últimas décadas, podem ser identificadas duas comunidades de políticas exercendo forte influência sobre o processo de decisão política federal 18,19. Nos anos 70 , a comunidade de política mais influente era formada por dirigentes públicos - do Instituto Nacional de Previdência Social (INPS), depois do Instituto Nacional de Assistência Médica e Previdência Social (INAMPS) e do Ministério da Saúde - que tinham conexões com a indústria farmacêutica, com entidades de prestadores privados de serviços, empresas de medicina de grupo, e organizações de profissionais de saúde, particularmente da área médica, por meio do Conselho Federal de Medicina, conselhos, associações e sindicatos médicos estaduais. Essa articulação política determinou a consolidação e expansão de um modelo de organização de serviços de saúde cuja característica central era a provisão privada oferecida nos centros urbanos, financiada com recursos da previdência social, controlada por mecanismos frágeis de regulação.

Durante os anos 80 e 90, a predominância dessa comunidade de política foi desafiada por uma comunidade que propôs e liderou a reforma do modelo consolidado na década anterior.
A última era formada por acadêmicos, pesquisadores, sindicatos de profissionais e trabalhadores de saúde e ficou conhecida como movimento sanitário. Ela criticava a organização do sistema de saúde brasileiro então vigente, e suas propostas eram inspiradas nos princípios defendidos na Declaração dos Cuidados Primários de Saúde e nos modelos inglês e cubano de atenção à saúde.

A arena política da área de saúde, aqui concebida como uma rede na qual as relações entre atores individuais e coletivos são assimétricas e muitas vezes conflitivas, nos últimos anos, sofreu alterações em sua configuração. O movimento sanitário, comunidade reformista formada ao final dos anos 70 do século passado, passou por um processo de diferenciação interna - ao menos em parte, produzido por mudanças no modo como o SUS passou a se organizar no país - que deu origem a uma nova comunidade 20,21.

A noção de configuração aqui empregada é definida como redes interdependentes de seres humanos, com relações de poder assimétricas estruturadas e mutantes 22 . O conceito é relevante para o presente estudo porque, como Elias $23 \mathrm{o}$ propôs, ressalta a interdependência dos atores, sejam eles indivíduos, sejam grupos, ao invés de salientar os antagonismos entre indivíduo e sociedade e entre grupos e instituições, como é prática recorrente nas análises entre Estado e sociedade. Para ele, não há dicotomia entre Estado e sociedade, ambos estão implicados em uma configuração social de poder que é constantemente recriada, mudando ainda que de forma incremental.

As instituições são tratadas aqui como regras explícitas e, principalmente, implícitas que produzem incentivos e constrangimentos à participação de atores. Se por um lado elas constrangem os modos de ação e organização de atores sociais, mas são as transformações nas configurações de relações entre atores estatais e societais que, por um lado, mantêm e, por outro, redefinem as instituições. Isso ocorre mesmo considerando que os resultados de políticas e as capacidades de reflexão e de ação desses atores sejam condicionadas por legados históricos institucionais e por configurações societais precedentes. É a articulação de atores societais e estatais individuais e coletivos em comunidades de política que pode alterar o formato e os espaços decisórios de arenas políticas setoriais e redefinir a configuração das relações entre atores e, portanto, suas posições nas estruturas hierarquizadas de relações que formam tais arenas 24,25,26,27,28. A perspectiva teórica apresentada nesta seção oferece as bases para a análise do processo de constituição e redefinição da arena política de saúde brasileira a 
partir da criação do SUS, focalizando o impacto sobre esta arena da constituição do novo CNS e das comissões intergestores.

\section{Arena política da área de saúde a partir da criação do SUS}

A realização da 8ạ Conferência Nacional de Saúde, no ano de 1986, é considerada como um dos principais marcos fundadores do processo de reforma que levou à criação do SUS 19. A Conferência estabeleceu os parâmetros normativos que guiaram as propostas daqueles que defendiam a reforma e deu origem à Comissão Nacional da Reforma Sanitária, que viria, em certa medida, a ser a precursora do "novo" CNS 20. A Comissão foi instalada ainda em 198629 com as finalidades de analisar as dificuldades da rede nacional de serviços de saúde e de sugerir uma nova estrutura organizacional do sistema. Coordenada pelo Secretário Geral do Ministério da Saúde, era integrada de forma paritária por representantes governamentais e societais.

As propostas da Comissão, o Relatório Final da 8a Conferência e a implementação do Programa dos Sistemas Unificados Descentralizados de Saúde (SUDS) fixaram uma agenda de tópicos a serem incluídos na Constituição Federal de 1988 que definiria os parâmetros legais do sistema. A comunidade de política movimento sanitário foi o ator protagonista na 8a Conferência, durante os trabalhos da Comissão, nos processos de elaboração e implementação do SUDS e nos debates que definiram o teor da seção sobre saúde no texto constitucional.

O novo CNS, criado em 1990, passou a ser deliberativo e responsável pela formulação de estratégias e pelo controle da execução da política de saúde nacional. Durante os primeiros anos da década ocupou lugar central na arena política da área. Paradoxalmente, foram as ações de atores governamentais e de atores sociais no CNS que vieram a consolidar o lugar secundário que ele passaria a ocupar nessa arena ao final da década e durante a década seguinte. A principal ação dos atores governamentais nesse sentido, capitaneada por representantes de gestores municipais e estaduais do CNS, foi o conjunto de iniciativas que conduziram à criação das comissões intergestores.

No início da década de 90, as dificuldades de gestão de um sistema de saúde em um estado federativo, como é o brasileiro, desafiavam os gestores e o movimento sanitário a encontrar mecanismos que viabilizassem a coordenação vertical e horizontal das ações implementadas de forma descentralizada. A proposta de criação das Comissões Bipartites, nos estados, e Tripartite no nível federal, como instâncias colegiadas de pactuação entre os gestores nos níveis de governo correspondentes foi articulada no CNS por representantes dos gestores municipais e estaduais 20. Em seguida, o CNS propôs ao Ministério da Saúde que fosse criada uma comissão especial para "discutir e elaborar propostas para implantação e operacionalização do SUS (...) a ser constituída pelas três instâncias gestoras governamentais" 30. O Ministério da Saúde, seguindo a recomendação do CNS, formou em 1991 "uma comissão técnica com o objetivo de discutir e elaborar propostas para implantação e operacionalização do Sistema Único de Saúde", que viria a ser conhecida como a Comissão Intergestores Tripartite (CIT) ${ }^{31}$.

A Norma Operacional Básica do Ministério da Saúde de 1993 (NOB/93) 32, além de aprofundar o processo de municipalização, formalizou a criação das comissões intergestores. Elaborada no início do Governo Itamar Franco, logo após o processo político que levara ao impedimento do Presidente Fernando Collor, foi construída em um ambiente político favorável, pois os novos dirigentes federais na área eram claramente identificados com o movimento sanitário, sendo mais permeáveis às propostas de aprofundamento da municipalização e da descentralização do sistema, se comparados aos gestores da administração Collor 33. Estabeleceu-se assim o desenho institucional de planejamento e de gestão do SUS até hoje vigente, caracterizado pela descentralização e pela existência de fóruns permanentes de coordenação vertical e horizontal.

A institucionalização das comissões intergestores teve impacto sobre o CNS. Tanto os conselheiros 20,21 quanto a literatura 33,34,35, salientam que as comissões passaram a ser os principais espaços institucionais de tomada de decisões sobre financiamento, coordenação da estrutura gestora descentralizada e funcionamento geral do SUS, o que afetou negativamente a capacidade do CNS em consolidar-se como um fórum central de decisão sobre a política de saúde nacional. Para os gestores que as idealizaram 20,21, havia a necessidade de coordenação das ações em saúde nos três níveis de governo para possibilitar a implementação de políticas nacionais de forma articulada e organizada. Para os representantes de entidades de profissionais e trabalhadores de saúde com atuação destacada no CNS, as comissões teriam tirado o protagonismo do CNS na definição das políticas de saúde. No entanto, a ação no interior do fórum desses atores sociais, sob a liderança dos representantes de entidades de profissionais e trabalhadores de saúde ao final dos anos 90 e durante a década seguinte, 
reafirmou o lugar secundário do CNS na arena política da área.

Entre 1990 e 2006, os conselheiros provenientes de entidades sociais gradativamente assumiram posição dominante no CNS. Ao longo do período, o número de representantes de organizações sociais no fórum cresceu tanto em termos relativos como absolutos, enquanto diminuiu a participação dos representantes governamentais e de mercado 20,21. Em 2005, esses conselheiros eram os mais assíduos às reuniões, eram aqueles que se manifestavam com maior freqüência durante as discussões e que coordenavam a maior parte das reuniões, além de serem também aqueles que mais vezes representaram o CNS em atividades externas. Havia uma preponderância relativa desses conselheiros na condução das discussões e deliberações, frente à menor participação de conselheiros governamentais e ao diminuto envolvimento de representantes de organizações de mercado. Segundo Silva et al. 21, um "núcleo duro" de seis conselheiros provenientes de entidades sociais influenciava fortemente as discussões e as deliberações que ocorriam no fórum. $\mathrm{O}$ "núcleo" era formado por quatro representantes de organizações de profissionais e trabalhadores de saúde e por dois representantes de entidades de portadores de patologias e deficiências, étnicas e de gênero.

O papel do CNS na arena setorial mudara. Ele constituía-se agora no principal espaço de articulação nacional de aliados e de difusão de idéias e propostas de uma nova comunidade de política que tinha como núcleo organizativo societal o Fórum de Entidades Nacionais de Trabalhadores da Área da Saúde (FENTAS). O FENTAS era o centro político - formulador de interpretações, propostas e estratégias de ação - da nova comunidade, cuja ação no CNS visava a fortalecer os laços entre representantes de categorias profissionais integrantes do FENTAS e outros líderes de entidades sociais. Os princípios fundadores do SUS integravam o conjunto de suas propostas, mas a eles acrescia-se a defesa da provisão exclusivamente pública de serviços e dos interesses trabalhistas de categorias de profissionais e de trabalhadores de saúde, não-médicos, em oposição a entidades que defendiam os interesses da categoria médica. Os gestores, profissionais de saúde e acadêmicos identificados com o movimento sanitário, que lideraram o processo de reforma do sistema brasileiro de saúde, eram vistos pela nova comunidade como integrantes de um grupo que renunciara aos verdadeiros ideais reformistas 21 . Assim, essa comunidade, articulada em torno do "núcleo duro" de integrantes do CNS, disputava com o movimento sanitário na arena política da área a condição de herdeira legítima do movimento reformista fundador do SUS.

Os atores sociais que passaram a liderar os trabalhos do CNS optaram por uma estratégia que visava a ampliar o seu controle sobre o fórum e não a fortalecê-lo como espaço decisório na arena política da área. Suas ações foram no sentido de, por um lado, concentrar as discussões no funcionamento do próprio CNS e no controle social no âmbito de todo o sistema. Desse modo, revigoravam sua hegemonia sobre o fórum e consolidavam o caráter nacional da nova comunidade de política ao articularem-se com conselheiros estaduais e municipais de todo o país. Por outro lado, buscavam acabar com a vaga cativa dos médicos e manter o número de representantes de gestores e de entidades de mercado reduzido, ao mesmo tempo em que pressionavam para retirar do Ministro da Saúde a prerrogativa de presidir o CNS 20.

No entanto, a vitória relativa da estratégia e a "conquista do poder" no CNS podem ter colaborado para que o poder do CNS na arena política da área tenha diminuído. Segundo Silva et al. 21, ao restringirem a influência dos representantes de entidades de mercado, dos médicos e de gestores no fórum estimularam que estes atores, que ocupavam posições centrais no processo decisório da área de saúde, buscassem defender seus interesses e apresentassem suas propostas em outros espaços políticos. Eles apenas reduziram a sua influência no CNS e não na arena política da área.

Enquanto os atores governamentais, especialmente gestores municipais e estaduais, concentravam suas atuações nas comissões intergestores, os atores de mercado optaram por exercer influência direta sobre os decisores governamentais e por estratégias de mercado que lhes garantissem posição privilegiada como provedores de serviços no âmbito do SUS e fora dele. Sua posição no sistema setorial, como provedores de serviços de saúde para o SUS e para o setor de seguros de saúde, foi fortalecida ao longo do período mediante subsídios públicos diretos e indiretos e por meio de escolhas estratégicas sobre os tipos de serviços oferecidos para estes dois complexos compradores. Como afirmam Santos \& Gerschman 34 (p. 798), através do apoio "à expansão de serviços e coberturas" e da consolidação de anéis burocráticos, a iniciativa privada pôde não apenas auferir os benefícios da contratação direta de serviços financiados pelo SUS como garantiu subsídios públicos para reforçar seu parque tecnológico. Para as autoras, “ao optar pela provisão privada como forma de viabilizar a universalização, (...) o setor público acaba criando e consolidando bases para a oferta privada de serviços" 34 (p. 798). 
O compromisso programático do movimento sanitário com a expansão dos serviços, as recomendações do Banco Mundial pela segmentação do sistema, as dificuldades de financiamento - agravadas com a perda dos recursos financeiros provenientes das contribuições sobre a folha de salário para previdência social -, a existência de um setor privado prestador e comprador de serviços criaram condições institucionais e políticas que favoreceram a permanência da provisão privada de serviços no âmbito do SUS e o fortalecimento da capacidade de barganha dos atores de mercado na arena política da área. Mas tal fortalecimento foi também o resultado da ação de representantes de interesses de mercado em espaços decisórios que não estavam abertos ao escrutínio público 34,35,36,37. Os "anéis burocráticos" construídos na década de 70, entre atores de mercado e os dirigentes do antigo INAMPS, foram revitalizados ou reconstituídos. Os recursos de poder desses atores viabilizaram ainda o exercício constante de pressões sobre o Poder Legislativo, a organização de campanhas na mídia em favor de suas demandas e propostas, e o acionamento do Poder Judiciário e do Ministério Público na defesa de seus interesses.

\section{Considerações finais}

Ao longo das duas décadas de existência do SUS, o CNS transitou de um lugar central para outro relativamente secundário na arena política setorial. Entretanto, a posição subordinada dos atores estatais e de mercado no interior do CNS, não significou que tenham deixado de ser dominantes na arena política setorial.

A criação das comissões intergestores, que se tornaram o principal espaço de negociação entre os três níveis de gestão do sistema, e a edição de normas legais e administrativas pelo Ministério da Saúde regrando o funcionamento do SUS e do setor mostram o fortalecimento do papel dos gestores federais. Nas comissões intergestores - fechadas à participação de atores sociais e de mercado - gestores estaduais e municipais, individualmente e por intermédio de suas cada vez mais influentes entidades associativas (Conselho Nacional de Secretários de Saúde - CONASS - e Conselho Nacional de Secretarias Municipais de Saúde - CONASEMS), estabeleceram canais diretos de relação com os gestores federais e ampliaram sua capacidade de ação sobre a arena política da área.

Os atores de mercado, por sua vez, mesmo sem participação nesses fóruns colegiados, continuaram a influir sobre as decisões governamentais. A robustez dos recursos de poder de que dispunham, as decisões tomadas por gestores federais e o legado institucional anterior à criação do SUS que os constituíra como o principal grupo de provedores de serviços de média e alta complexidades para o setor público, favoreceram tal continuidade e que se ampliassem as possibilidades de sua inserção lucrativa no setor.

A posição dominante desses dois tipos de atores, no entanto, não deve obscurecer a novidade que representou na arena política da área a presença atuante de atores sociais. A criação de mecanismos participativos, particularmente dos conselhos, fez surgir uma cadeia de fóruns institucionalizados em cujo topo se localiza o CNS. Mesmo com posição relativamente secundária na arena setorial, o CNS e os atores nele preponderantes podiam influir sobre o processo decisório da área ou ao menos contestar decisões que fossem consideradas contrárias aos seus interesses ou aos princípios que defendiam. Outra novidade foi a formação de uma nova comunidade de política cujo centro de atuação é exatamente o CNS. Futuros estudos poderão examinar a natureza dessa comunidade e verificar se confirmamse as indicações de que ela se estrutura como uma rede hierarquizada de relações entre atores individuais e coletivos, cujas posições superiores são ocupadas por profissionais de saúde. 


\section{Resumo}

O artigo analisa o impacto da criação do novo Conselho Nacional de Saúde, em 1990, e das comissões intergestores, em 1993, sobre a arena política de saúde e sobre a configuração das relações entre atores estatais e societais no âmbito do Sistema Único de Saúde. As três principais conclusões do artigo são as seguintes: a criação de fóruns nos quais atores estatais podem construir acordos que viabilizem a coordenação federativa das ações de gestão fortaleceu as posições desses atores na arena política da área; atores sociais, liderados por representantes de entidades de profissionais de saúde, foram compelidos, mas também buscaram ativamente, a apresentar suas demandas e propostas em fóruns participativos que tratavam principalmente de questões políticas secundárias, perdendo assim, ao longo do período, capacidade de influir sobre o processo decisório da área; atores de mercado pouco se envolveram em fóruns participativos, dando preferência a exercer influência diretamente sobre os decisores públicos e a implementar estratégias adaptativas para aumentar seus lucros.

Sistema Único de Saúde; Política de Saúde; Conselhos de Saúde; Profissional de Saúde

\section{Referências}

1. Fligstein N, Sweet AS. Constructing polities and markets: an institutionalist account of European integration. Am J Sociol 2002; 107:1206-43.

2. Yáñez CJN, Magnier A. Local governance as government business cooperation in Western democracies: analysing local and intergovernmental effects by multi-level comparison. Int J Urban Reg Res 2008; 32:531-47.

3. Gramsci A. Cadernos do cárcere. Rio de Janeiro: Editora Civilização Brasileira; 2004.

4. Bourdieu P. Razões práticas: sobre a teoria da ação. Campinas: Papirus Editora; 1996.

5. Bonfim WLS, Fernandes ASA. Teorias democráticas contemporâneas e o caso brasileiro pós-Constituição de 1988. In: Anais do XXVIII Encontro Anual da ANPOCS. Caxambu: Associação Nacional de Pósgraduação e Pesquisa em Ciências Sociais; 2004.

6. Edwards B, Folley M. Civil society and social capital beyond Putnam. Am Behav Sci 1998; 42:124-39.

7. Lavalle AG. Sem pena nem glória: o debate sobre a sociedade civil nos anos 1990. Novos Estudos CEBRAP 2003; 66:91-109.
8. Silva MK. Entre a norma e o factual: questões para uma análise sociológica dos processos de participação social na gestão pública. Política e Sociedade 2004; 1:185-200.

9. Pinto CRJ. Espaços deliberativos e a questão da representação. Rev Bras Ciênc Soc 2004; 19:97-116.

10. Cohen JL. Sociedade civil e globalização: repensando categorias. Dados Rev Ciênc Sociais 2003; 46:419-59.

11. Lee K, Mills A. Policy-making and planning in the health sector. London: Croom Helm; 1985.

12. Walt G. Health policy: an introduction to process and power. London: Zed Books; 1994.

13. Heclo H. Issue network and the executive establishment. In: King A, editor. The new American political system. Washington DC: American Enterprise Institute for Public Policy Research; 1978. p. 87-124.

14. Rodes RAW. The national world of local government. Oxford: Allen and Unwin; 1986.

15. Jordan G, Richardson JJ. Governing under pressure. Oxford: Martin Robertson; 1979. 
16. Dunleavy P. Professions and policy change: notes towards a model of ideological corporatism. Public Administration Bulletin 1981; 36:3-16.

17. True JL, Jones BD, Baumgartener FR. Punctuated-equilibrium theory: explaining stability and change in public policy making. In: Sabatier PA, editor. Theories of the policy process. Boulder: Westview Press; 2007. p. 155-87.

18. Paim JS. As políticas de saúde e a conjuntura atual. Espaço para a Saúde 1989; 1:18-24.

19. Teixeira SMF. Política de saúde na transição conservadora. Saúde Debate 1989; 26:42-53.

20. Côrtes SMV, Silva MK, Reos JC, Barcelos M. Conselho Nacional de Saúde: histórico, papel institucional e atores estatais e societais. In: Côrtes SMV, organizadora. Participação em saúde no Brasil. Rio de Janeiro: Editora Fiocruz; no prelo.

21. Silva MK, Côrtes SMV, Reos JC, Barcelos M. A dinâmica das relações sociais no Conselho Nacional de Saúde. In: Côrtes SMV, organizadora. Participação em saúde no Brasil. Rio de Janeiro: Editora Fiocruz; no prelo.

22. Bergh GBD. The structure of development: an invitation to the sociology of Norbert Elias. The Hague: Institute of Social Studies; 1971. (I.S.S. Occasional Paper, 13).

23. Elias N. O processo civilizador. Rio de Janeiro: Jorge Zahar; 1993.

24. Evans P. Além da monocultura institucional: instituições, capacidades e o desenvolvimento deliberativo. Sociologias 2003; 5:20-63.

25. Hay C. Political analysis: an introduction. Basingstoke: Palgrave; 2002.

26. Jessop B. 2003. Bringing the state back in (yet again): reviews, revisions, rejections and redirections. http:/ / www.lancs.ac.uk/sociology/papers / Jessop-Bringing-The-State-Back-In.pdf (acessado em 15/Set/2008).

27. Pierson P. Dismantling the Welfare State? Reagan, Thatcher, and the politics of retrenchment. Cambridge: Cambridge University Press; 1994.

28. Skocpol T. Bringing the State back in: strategies of analysis in current research. In: Evans P, Rue- schemeyer D, Skocpol T, editors. Bringing the State back in. New York: Cambridge University Press; 1985. p. 3-37.

29. Brasil. Portaria no. 2. Constitui a Comissão Nacional da Reforma Sanitária, com a finalidade de analisar as dificuldades identificadas no funcionamento da rede nacional de serviços de saúde, e sugerir opções para a nova estrutura organizacional do sistema. Diário Oficial da União 1986; 2 ago.

30. Conselho Nacional de Saúde. Resolução no. 2. Recomenda ao Ministro da Saúde a constituição de uma comissão especial para elaborar propostas na implantação e operacionalização do SUS. http:// conselho.saude.gov.br/resolucoes/reso_91.htm (acessado em 21/Mai/2007).

31. Brasil. Portaria no. 1.180. Cria a comissão técnica com o objetivo de discutir e elaborar propostas para implantação e operacionalização do Sistema Único de Saúde, incluindo as questões de gerenciamento e financiamento do SUS. Diário Oficial da União 1991; 22 jul.

32. Brasil. Portaria no. 545. Norma Operacional Básica do Sistema Único de Saúde. Diário Oficial da União 1993; 24 mai.

33. Levcovitz E, Lima LD, Machado CV. Política de saúde nos anos 90: relações intergovernamentais e o papel das Normas Operacionais Básicas. Ciênc Saúde Coletiva 2001; 6:269-91.

34. Santos MAB, Gerschman S. O Sistema Único de Saúde como desdobramento das políticas de saúde do século XX. Rev Bras Ciênc Soc 2006; 21:177-90.

35. Menicucci TMG. Público e privado na política de assistência à saúde no Brasil. In Anais do $4^{\circ}$ Encontro da ABCP. Rio de Janeiro: Academia Brasileira de Ciência Política; 2004.

36. Cohn A. Mudanças econômicas e políticas de saúde no Brasil. In: Laurell AC, organizadora. Estado e políticas sociais no neoliberalismo. São Paulo: Cortez Editora/Centro de Estudos de Cultura Contemporânea; 1995. p. 225-44.

37. Labra ME. Associativismo no setor saúde brasileiro e organizações de interesse do empresariado médico. Physis (Rio J.) 1993; 3:193-225.

Recebido em 09/Mar/2009

Aprovado em 18/Mai/2009 